\title{
Tolerance to Ethanol or Nicotine Results in Increased Ethanol Self-Administration and Long-Term Depression in the Dorsolateral Striatum
}

\author{
Chandrika Abburi, ${ }^{1, "}$ Shannon L. Wolfman, ${ }^{2,}{ }^{,}$Ryan A. E. Metz, ${ }^{1}$ Rinya Kamber, ${ }^{1}$ DDaniel S. McGehee, ${ }^{1,2}$ \\ and ${ }^{(D)}$ John McDaid ${ }^{1}$
}

DOI:http://dx.doi.org/10.1523/ENEURO.0112-15.2016

${ }^{1}$ Department of Anesthesia and Critical Care, University of Chicago, Chicago, Illinois 60637, and ${ }^{2}$ Committee on Neurobiology, University of Chicago, Chicago, Illinois 60637

\begin{abstract}
Ethanol $(\mathrm{EtOH})$ and nicotine are the most widely coabused drugs. Tolerance to EtOH intoxication, including motor impairment, results in greater EtOH consumption and may result in a greater likelihood of addiction. Previous studies suggest that cross-tolerance between $\mathrm{EtOH}$ and nicotine may contribute to the abuse potential of these drugs. Here we demonstrate that repeated intermittent administration of either EtOH or nicotine in adult male Sprague Dawley rats results in tolerance to EtOH-induced motor impairment and increased EtOH self-administration. These findings suggest that nicotine and EtOH cross-tolerance results in decreased aversive and enhanced rewarding effects of $\mathrm{EtOH}$. Endocannabinoid signaling in the dorsolateral striatum (DLS) has been implicated in both EtOH tolerance and reward, so we investigated whether nicotine or $\mathrm{EtOH}$ pretreatment might modulate endocannabinoid signaling in this region. Using similar EtOH and nicotine pretreatment methods resulted in increased paired-pulse ratios of evoked EPSCs in enkephalin-positive medium spiny neurons in DLS slices. Thus, EtOH and nicotine pretreatment may modulate glutamatergic synapses in the DLS presynaptically. Bath application of the CB1 receptor agonist Win 55,2-212 increased the paired-pulse ratio of evoked EPSCs in control slices, while Win 55,2-212 had no effect on paired-pulse ratio in slices from either $\mathrm{EtOH}$ - or nicotine-pretreated rats. Consistent with these effects, nicotine pretreatment occluded LTD induction by high-frequency stimulation of the corticostriatal inputs to the dorsolateral striatum. These results suggest that nicotine and $\mathrm{EtOH}$ pretreatment modulates striatal synapses to induce tolerance to the motor-impairing effects of $\mathrm{EtOH}$, which may contribute to nicotine and $\mathrm{EtOH}$ coabuse.
\end{abstract}

Key words: addiction; reward; endocanabinoid; motor impairment; self-administration

\section{Significance Statement}

This study demonstrates that repeated intermittent nicotine or ethanol pre-exposure results in lower levels of ethanol-induced motor impairment and higher levels of ethanol self-administration. These effects of pretreatment suggest cross-tolerance between these drugs, which may contribute to the development of dependence. These studies identify cellular mechanisms underlying the development of ethanol tolerance that may lead to novel treatments for alcohol and nicotine dependence.

\section{Introduction}

Ethanol (EtOH) and nicotine addiction are two of the leading causes of preventable death worldwide. These

Received September 21, 2015; accepted July 13, 2016; First published July 19, 2016.

The authors declare no competing financial interests. are the most commonly coabused drugs, with a large majority of alcoholics diagnosed with a comorbid addiction to nicotine (Miller and Gold, 1998). In fact, alcoholics 
who are also smokers drink more, have stronger cravings, and are more severely alcohol dependent (Batel et al., 1995; York and Hirsch, 1995; Glautier et al., 1996; Daeppen et al., 2002; Rose et al., 2002; Sayette, 2002; John et al., 2003; Hertling et al., 2005; Acheson et al., 2006; Barrett et al., 2006; King et al., 2010; Buu et al., 2014; McClure et al., 2015). Many factors likely contribute to the prevalence of $\mathrm{EtOH}$ and nicotine coabuse, and understanding the neurobiological underpinnings may help to identify novel treatments for addiction to these two drugs.

Cross-tolerance to the aversive effects of $\mathrm{EtOH}$ and nicotine likely facilitates the coabuse of these drugs, as nicotine enhances the rewarding effects of $\mathrm{EtOH}$, while attenuating some of the more negative sedative and cognitive effects (Perkins et al., 1995; Collins et al., 1996b; Söderpalm et al., 2000; Schuckit et al., 2001; Johnson, 2004; Ceballos, 2006; Funk et al., 2006; Morrow et al., 2006). Numerous studies have examined cross-tolerance between $\mathrm{EtOH}$ and nicotine; however, the behavioral tasks, drug doses, and administration methods vary widely (Potthoff et al., 1983; Collins et al., 1988; Burch et al., 1988; Blomqvist et al., 1996; López-Moreno et al., 2008; Biała and Budzyńska, 2010; Lê et al., 2014). We know that exposure to $\mathrm{EtOH}$ or nicotine alters neural circuitry underlying reward and sedation/cognition, but a link between these two behavioral end points in the context of cross-tolerance has not been established. Therefore, we investigated the effects of cross-tolerance between ethanol and nicotine on both reward- and sedation-related behaviors.

In humans, smoking history can predict future $\mathrm{EtOH}$ dependence (John et al., 2003; Buu et al., 2014), which suggests that previous exposure to nicotine impacts the behavioral effects of EtOH, even in the absence of concurrent nicotine exposure. For our studies, moderate, physiologically relevant doses of both drugs were used to test the hypothesis that nicotine pre-exposure would enhance EtOH self-administration and decrease EtOHinduced motor impairment. We also predicted that a common neurobiological change would accompany these behavioral changes.

As the dorsolateral striatum (DLS) is involved both in the rewarding and motor effects of $\mathrm{EtOH}$ and nicotine (Meng et al., 1998; Garção et al., 2013; Chen et al., 2014), we focused our electrophysiology investigations on this brain

This research was supported by NIH Grant DA07255 to S.L.W.; NIH Grant AA020082 to J.M. and D.S.M.; and NIH Grants DA036978 and NS095374 to D.S.M.

*C.A. and S.L.W. contributed equally to this work.

J. McDaid's present address: Department of Neuroscience, Rosalind Franklin University of Medicine and Science, 3333 Green Bay Road, North Chicago, IL 60064-3095.

Correspondence should be addressed to either Daniel S. McGehee or John McDaid, Department of Anesthesia \& Critical Care, University of Chicago, 5841 South Maryland Avenue, MC4028, Chicago, IL 60637, Email: john.mcdaid@rosalindfranklin.edu or dmcgehee@uchicago.edu.

DOI:http://dx.doi.org/10.1523/ENEURO.0112-15.2016

Copyright $\odot 2016$ Abburi et al.

This is an open-access article distributed under the terms of the Creative Commons Attribution 4.0 International, which permits unrestricted use, distribution and reproduction in any medium provided that the original work is properly attributed. region. $\mathrm{EtOH}$ and nicotine modulate endocannabinoid signaling in the DLS (González et al., 2002; Marco et al., 2007; Adermark et al., 2011; Vinod et al., 2012; DePoy et al., 2013, 2015), and CB1 receptor agonists produce cross-tolerance with both $\mathrm{EtOH}$ and nicotine (Sprague and Craigmill, 1976; Siemens and Doyle, 1979; da Silva et al., 2001; Valjent and Mitchell, 2002; Lemos et al., 2007; Biała and Budzyńska, 2010). Additionally, the administration of either $\mathrm{EtOH}$ or nicotine results in increased endocannabinoid release and decreased CB1 receptor expression (Basavarajappa et al., 1998; Hungund and Basavarajappa, 2000; González et al., 2002; Marco et al., 2007; Adermark et al., 2011; Vinod et al., 2012; DePoy et al., 2013). Therefore, we investigated the effects of both $\mathrm{EtOH}$ and nicotine pretreatment on cannabinoid signaling in the DLS, and how these effects correlate with $\mathrm{EtOH}$ reward and motor impairment.

\section{Materials and Methods}

\section{Animals}

Adult male Sprague Dawley rats [postnatal day 60 (P60) to P90; Harlan] were housed two per cage with a $12 \mathrm{~h}$ reverse light/dark cycle and ad libitum access to food and water. During EtOH self-administration, rats were singly housed. All animal procedures were performed in accordance with the regulations of the University of Chicago animal care committee.

\section{Drugs and reagents}

All drugs and reagents were obtained from SigmaAldrich, unless otherwise noted. Nicotine hydrogen tartrate salt was used for nicotine treatments, and $99 \%$ ethanol was used for EtOH treatments, as described in greater detail below.

\section{Rotarod testing}

On training day, rats were placed on the rotarod (Rotamex 5, Columbus Instruments) at a fixed speed of $4 \mathrm{rpm}$. After each animal demonstrated an ability to stay on the rotarod at this speed for $\sim 10 \mathrm{~s}$, the speed was increased at a rate of $1 \mathrm{rpm}$ every $5 \mathrm{~s}$ until the last animal fell off. This protocol was repeated for a total of 10 consecutive trials, after which the animals were placed back in their home cages. Three days later, animals were tested for rotarod performance. Over a set of four consecutive trials, baseline performance was assessed. Immediately following completion of the baseline trials, rats were injected with either nicotine $(0.1 \mathrm{mg} / \mathrm{kg}$, s.c., as base), vehicle (PBS, 1 $\mathrm{ml} / \mathrm{kg}$, s.c.), or EtOH (1 g/kg, i.p., $50 \%$ in PBS), depending on the experiment. Fifteen minutes after injection, rotarod performance was again tested over a set of four consecutive trials. A total of six sets of four trials were conducted at $15 \mathrm{~min}$ intervals, including the baseline trials. For experiments with repeated rotarod testing, the same protocol was used for the next $2 \mathrm{~d}$. On the last day, the same protocol was used, but all rats received $\mathrm{EtOH}$ injections.

\section{Home-cage pretreatment}

Rats received injections of either PBS (1 ml/kg, s.c.), nicotine $(0.1 \mathrm{mg} / \mathrm{kg}$, s.c., as base, once per day), or EtOH (1 g/kg, s.c., $50 \%$ in PBS, twice per day $4 \mathrm{~h}$ apart) for 3 
consecutive days. EtOH injection schedule was chosen to ensure several hours of a moderate blood EtOH concentration. Animals in the rotarod experiments were given home-cage injections $3 \mathrm{~d}$ after rotarod training, and rotarod testing commenced the day following the final home-cage injection. Animals in the self-administration experiments were given access to the two-bottle choice test the day following the final home-cage injection. Animals used for slice experiments were killed the day following the final home-cage injection.

\section{EtOH self-administration}

Rats were singly housed for $3 \mathrm{~d}$ before receiving homecage injections. The day after the final injection, rats were given continuous access to two drinking bottles in the home cage. One contained water, and the other contained $20 \% \mathrm{EtOH}(\mathrm{v} / \mathrm{v})$ in water. Water and $\mathrm{EtOH}$ consumption were measured every $48 \mathrm{~h}$ by weighing the bottles. The bottles were switched between sides after every measurement in order to control for side preferences. Self-administration continued for $20 \mathrm{~d}$.

\section{Electrophysiology}

The day following the final home-cage injection, rats were decapitated under isoflurane anesthesia, and brains were removed and transferred into ice-cold NMDG solution (in mM: $N$-acetyl-cysteine 12, NMDG 93, KCl 2.5, $\mathrm{NaH}_{2} \mathrm{PO}_{4}$ 1.2, $\mathrm{NaHCO}_{3} 30$, HEPES 20, glucose 25, sodium ascorbate 5 , thiourea 1.97 , sodium pyruvate 3 , $\mathrm{MgSO}_{4}\left(7 \mathrm{H}_{2} \mathrm{O}\right) \quad 10, \mathrm{CaCl}_{2}\left(2 \mathrm{H}_{2} \mathrm{O}\right) 0.5, \mathrm{pH} 7.4$ with $\mathrm{HCl}$; bubbled continuously with $95 \% \mathrm{O}_{2} / 5 \% \mathrm{CO}_{2}$ ). The $250 \mu \mathrm{m}$ coronal slices containing the striatum were obtained with vibrating blade microtome (VT1000 S, Leica) in NMDG protective slicing solution (Zhao et al., 2011). Slices were transferred to an NMDG-containing holding chamber and allowed to recover for $10 \mathrm{~min}$ at $32^{\circ} \mathrm{C}$. The slices were then moved to a holding chamber perfused with modified HEPES holding aCSF (in mM: N-acetyl-cysteine 12, $\mathrm{NaCl}$ 92, $\mathrm{KCl} 2.5, \mathrm{NaH}_{2} \mathrm{PO}_{4} 1.2, \mathrm{NaHCO}_{3} 30$, HEPES 20, glucose 25 , sodium ascorbate 5 , thiourea 1.97 , sodium pyruvate $3, \mathrm{MgSO}_{4}\left(7 \mathrm{H}_{2} \mathrm{O}\right) 2, \mathrm{CaCl}_{2}\left(2 \mathrm{H}_{2} \mathrm{O}\right) 2, \mathrm{pH} 7.4$ with $\mathrm{NaOH}$; bubbled continuously with $95 \% \mathrm{O}_{2} / 5 \% \mathrm{CO}_{2}$ ) at a rate of $20 \mathrm{ml} / \mathrm{min}$ for at least $30 \mathrm{~min}$ at $32^{\circ} \mathrm{C}$. For recording, slices were transferred to a recording chamber superfused with aCSF (in mM: $\mathrm{NaCl} 125, \mathrm{KCl} 2.5, \mathrm{MgCl}_{2} 1$, $\mathrm{CaCl}_{2} 2.5$, glucose 20, $\mathrm{NaH}_{2} \mathrm{PO}_{4} 1, \mathrm{NaHCO}_{3} 25$, ascorbic acid 1 ; bubbled with $95 \% \mathrm{O}_{2} / 5 \% \mathrm{CO}_{2}$ ) at a rate of 2 $\mathrm{ml} / \mathrm{min}$. Recordings were performed at room temperature (RT). The dorsolateral striatum was identified according to Paxinos and Watson (1998), and medium spiny neurons (MSNs) were visualized under infrared illumination using an upright microscope (BX51WI, Olympus). Standard whole-cell voltage-clamp recordings used a multiclamp 700B amplifier, a Digidata 1440 interface, and Clampex version 10.4 software (Molecular Devices). All recordings were filtered at $1 \mathrm{kHz}$ and digitized at $5 \mathrm{kHz}, V_{\mathrm{m}}=-70$ $\mathrm{mV}$. For all recordings, we used borosilicate electrodes pulled to a resistance of 3-7 $\mathrm{M} \Omega$ and containing a recording solution consisting of (in $\mathrm{mM}$ ), cesium gluconate 117, HEPES 20, EGTA 0.4, NaCl 2.8, ATP 2.5, GTP 0.25, glucose 20, TEA 5, QX314 5, biocytin, 0.01\% (AnaSpec,
Inc.; $\mathrm{pH} 7.4$ with $\mathrm{CsOH}$ ). Series resistance was $<20 \mathrm{M} \Omega$, cells that reached higher resistances during the course of recording were discarded. All recordings were conducted in the presence of $20 \mu \mathrm{m}$ bicuculline (Tocris Bioscience) to limit indirect effects from GABAergic synaptic inputs. EPSCs were evoked during recording from MSNs using a bipolar platinum-iridium-stimulating electrode placed inside the cortical border of the DLS. This placement favors the activation of corticostriatal synaptic inputs.

\section{Paired-pulse ratios}

To obtain paired-pulse ratios, we used a $50 \mathrm{~ms}$ interstimulus interval between evoked EPSCs, and the ratio was calculated as the second EPSC amplitude/the first EPSC amplitude (P2/P1). To compare the effect of in vivo pretreatment with nicotine or $\mathrm{EtOH}$, three consecutive paired-pulses were obtained at $1 \mathrm{~min}$ intervals and averaged for each neuron tested. For testing the CB1 agonist, we obtained paired-pulse EPSCs at 1 min intervals until 5 min of consistent P2/P1 ratios were observed. The CB1 agonist Win 55,2-212 (Tocris Bioscience) was then bath applied at a concentration of $5 \mu \mathrm{M}$, and the P2/P1 ratio was monitored at $1 \mathrm{~min}$ intervals for at least $20 \mathrm{~min}$.

\section{HFS-induced long-term depression}

Long-term depression (LTD) in MSNs was induced by stimulating corticostriatal glutamatergic fibers with highfrequency stimulation (HFS) consisting of a single train, with $1 \mathrm{~s}$ duration and $100 \mathrm{~Hz}$ frequency, after $5-10 \mathrm{~min}$ of stable baseline recordings. $V_{\mathrm{m}}=-70 \mathrm{mV}$ throughout the recording and HFS stimulation. Average EPSC amplitudes from 20-30 min post-HFS were normalized to the average of EPSCs recorded during the $10 \mathrm{~min}$ baseline period for each neuron tested. These normalized values from nicotine- and vehicle-pretreated animals were pooled and compared using an unpaired $t$ test.

\section{Immunohistochemistry}

The internal solution used during whole-cell recordings contained biocytin $(0.01 \%)$ for post hoc identification of the recorded cells. Enkephalin immunostaining allowed for the determination of the MSN subtype from which the recording was done (McGinty, 2007). Slices were fixed in $4 \%$ paraformaldehyde overnight after recording. Fixed slices were washed three times with $1 \times$ PBS (each wash for $5 \mathrm{~min}$ ) and then blocked in $1 \times$ PBS containing $1 \%$ Triton X-100, 10\% normal donkey serum, and 1\% bovine serum albumin for $30 \mathrm{~min}$ at RT. The slices were incubated with $1^{\circ}$ goat pAb to enkephalin (1:200; ab77273, Abcam) in blocking solution overnight at RT. Following three washes in $1 \times$ PBS, slices were incubated with Alexa Fluor 488 Donkey anti-goat IgG (1:1000; Invitrogen) and streptavidin Alexa Fluor 594 conjugate (1:1000; Invitrogen) for $3 \mathrm{~h}$ at room temperature. Finally, slices were washed three times with PBS, mounted, and coverslipped with Fluoromount-G (Southern Biotech). Stained slices were imaged under a fluorescent microscope to determine colocalization of enkephalin and biocytin.

\section{Data analysis and statistics}

All electrophysiology data was collected using Clampex version 10.4 (Molecular Devices). Evoked EPSCs were 
A

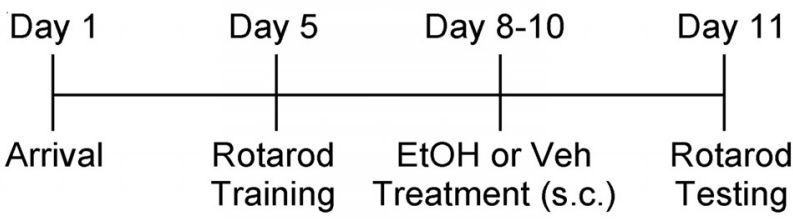

B

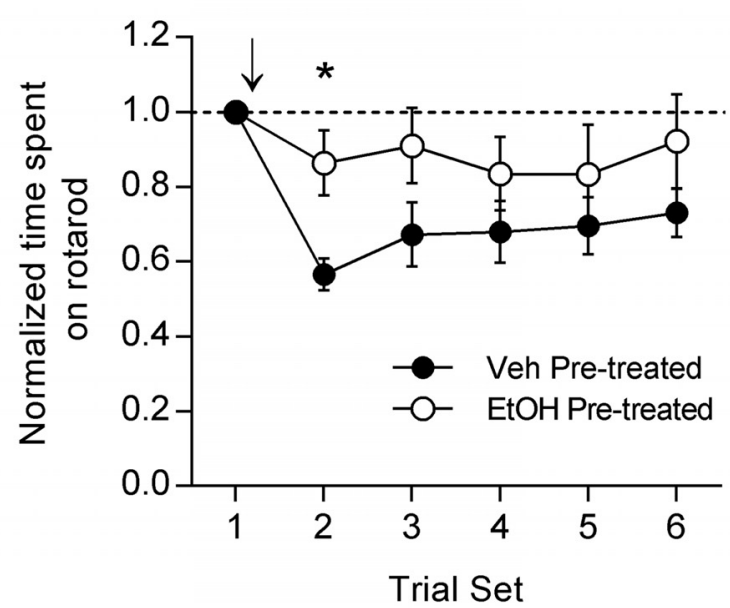

C

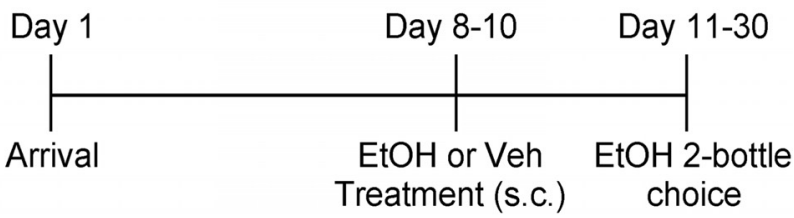

D

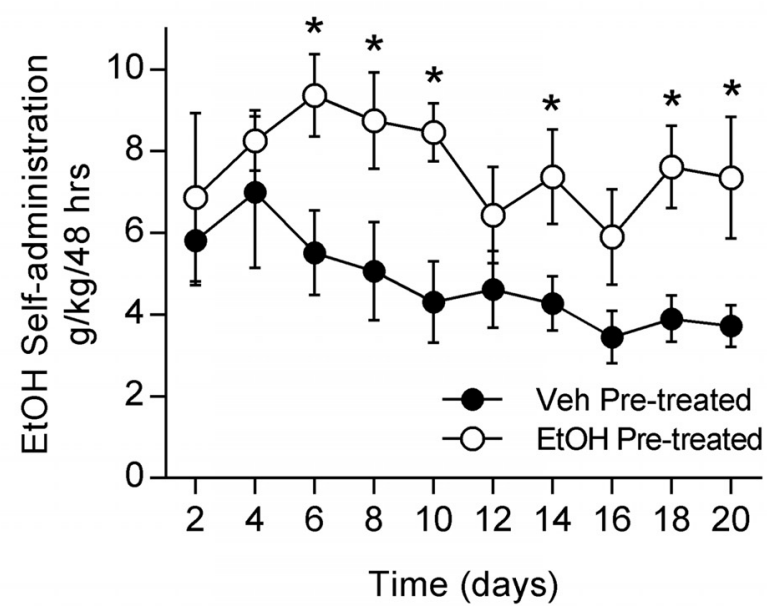

Fig. 1. EtOH pretreatment results in tolerance to $\mathrm{EtOH}$-induced motor impairment and increased EtOH self-administration. $\boldsymbol{A}$, Timeline for the rotarod experiment in which rats were pretreated in the home cage with either $\mathrm{EtOH}$ or vehicle. $\boldsymbol{B}$, Animals previously trained on the accelerating rotarod and pretreated for $3 \mathrm{~d}$ with either EtOH (1 g/kg, s.c., twice per day) or vehicle were tested for the effects of EtOH (1 g/kg, i.p.) on rotarod performance. Arrow indicates the time at which acute EtOH was administered. EtOH-pretreated animals displayed less impair-
Fig. 1. continued

ment on the rotarod after acute $\mathrm{EtOH}$ administration than did the vehicle-treated animals (ANOVA, $p=0.0664$; Holm-Sidak post hoc test, $* p<0.05$; EtOH, $n=6$; vehicle, $n=7$ ). $\boldsymbol{C}$, Timeline for the EtOH two-bottle choice self-administration experiment in which rats were pretreated in the home cage with either $\mathrm{EtOH}$ or vehicle. $\boldsymbol{D}$, Animals pretreated with $\mathrm{EtOH}(1 \mathrm{~g} / \mathrm{kg}$, s.c., twice per day) or vehicle were given $24 \mathrm{~h}$ access to both a bottle of water and a bottle of $20 \% \mathrm{EtOH}$ for $20 \mathrm{~d}$. EtOH pretreated animals self-administered more $\mathrm{EtOH}$ than vehicle-pretreated animals (ANOVA, $p<0.05$; Holm-Sidak post hoc test, $* p<0.05 ; n=8$ for both groups).

analyzed using Clampfit (Molecular Devices). Two-way repeated-measures (RM) ANOVA followed by a HolmSidak post hoc test was used to determine the effects of $\mathrm{PBS} /$ nicotine/EtOH pretreatments on behavioral tasks. One-way ANOVA was used to analyze the effects of pretreatments on EPSC amplitudes and the paired-pulse ratios of evoked EPSCs. Paired $t$ test was used for analysis of CB1 agonist effects; comparison was made between the baseline for each treatment group and the effects of the agonist. An unpaired $t$ test was used to assess differences in LTD induction between nicotineand vehicle-treated rats. All statistical tests were performed using SigmaPlot (Systat), and all results are presented as the mean \pm SEM.

\section{Results}

\section{Tolerance to EtOH increases EtOH self-administration}

Motor impairment is a key adverse effect of $\mathrm{EtOH}$, and tolerance to this aversive effect may promote escalated drinking. We first wanted to determine whether $\mathrm{EtOH}$ pretreatment in the home cage was sufficient in our hands to produce tolerance to the motor-impairing effects of $\mathrm{EtOH}$. We used a physiologically relevant dose of EtOH (1 $\mathrm{g} / \mathrm{kg}$, i.p., $50 \%$ in PBS) and administered either $\mathrm{EtOH}$ or vehicle (PBS) twice per day for $3 \mathrm{~d}$. We then used an accelerating rotarod to test motor performance in response to a challenge dose of $\mathrm{EtOH}(1 \mathrm{~g} / \mathrm{kg}$, i.p.; Fig. $1 A)$. Because we were interested in examining the effects of $\mathrm{EtOH}$ pretreatment on rotarod performance rather than learning, we trained the rats on the rotarod prior to the first exposure to $\mathrm{EtOH}$. Training consisted of 10 consecutive trials on the rotarod during $1 \mathrm{~d}$. This protocol resulted in a consistent level of baseline performance on the testing day.

On testing day, the rats were subjected to one set of four consecutive trials to establish baseline performance (trial set 1). Animals then received a challenge injection of $\mathrm{EtOH}$ and were tested in five additional sets of trials. Trial 2 began 15 min after EtOH administration, and subsequent trials were performed in 15 min intervals. EtOH pretreatment in the home cage resulted in decreased motor impairment in response to an acute EtOH challenge compared with vehicle pretreatment (Fig. 1B; two-way RM ANOVA, $p=0.0664$ time $\times$ treatment interaction; HolmSidak test for multiple comparisons, $p=0.0119$; EtOH 
group, $n=6$; PBS group, $n=7$ ). This suggests that this limited, intermittent EtOH pretreatment was sufficient to produce tolerance to the motor-impairing effects of acute $\mathrm{EtOH}$. This experiment confirmed past findings of tolerance to the motor-impairing effects of EtOH (Siemens and Doyle, 1979; Batista et al., 2005; Werner et al., 2009) and provided a baseline to which we could compare the possible effects of $\mathrm{EtOH}$-nicotine cross-tolerance on the motor-impairing effects of EtOH.

We then tested whether the same $\mathrm{EtOH}$ pretreatment that produces tolerance to $\mathrm{EtOH}$ would also be sufficient in our hands to increase $\mathrm{EtOH}$ self-administration. We singly housed the rats and used the same dose and schedule of EtOH pretreatment. We then gave the rats 24 $\mathrm{h}$ access to two bottles, one that contained water, and one that contained $20 \% \mathrm{EtOH}$ during the two-bottle choice self-administration procedure for $20 \mathrm{~d}$ (Fig. 1C). $\mathrm{EtOH}$ and water consumption were measured every $48 \mathrm{~h}$ by weighing the bottles. The sides on which the bottles were placed were alternated after every measurement to avoid the potential confound of a side preference. EtOH pretreatment resulted in increased EtOH self-administration compared with vehicle pretreatment (Fig. 1D; two-way RM ANOVA, $p=0.011$ between treatments; Holm-Sidak test for multiple comparisons: day $6, p=$ 0.014 ; day $8, p=0.018$; day $10, p=0.008$; day $14, p=$ 0.045 ; day $18, p=0.017$; day $20, p=0.02 ; n=8$ in each group). These results are consistent with previous findings that $\mathrm{EtOH}$ pretreatment enhances $\mathrm{EtOH}$ self-administration (Deutsch and Koopmans, 1973; Fidler et al., 2011). However, we used lower, more physiologically relevant doses of $\mathrm{EtOH}$ than have most prior studies, and we administered $\mathrm{EtOH}$ less frequently. Additionally, our data suggest that tolerance to $\mathrm{EtOH}$ can contribute to enhanced EtOH intake.

\section{Nicotine pretreatment results in tolerance to EtOH-induced motor impairment and increased EtOH self-administration}

To explore the effects of nicotine on $\mathrm{EtOH}$-induced motor impairment, we again used the accelerating rotarod. We were also interested in testing the acute effects of nicotine on rotarod performance. After training on the rotarod was completed, rotarod testing began in conjunction with daily nicotine treatments. After the baseline trial set, nicotine $(0.1 \mathrm{mg} / \mathrm{kg}$, s.c.) or vehicle was administered. After 15 min, trial set 2 began, and subsequent trial sets continued at $15 \mathrm{~min}$ intervals. This combination of nicotine or vehicle administration and rotarod testing was performed for $3 \mathrm{~d}$. Acute nicotine administration caused impairment on the rotarod compared to vehicle administration on all $3 \mathrm{~d}$ (Fig. 2; two-way RM ANOVA, day 1, 2, 3: $p<0.0001$ between treatments; Holm-Sidak test for multiple comparisons: day 1 trial set $2, p=0.006$; day 2 trial set $2, p=0.003$; day 2 trial set $3, p=0.0314$; day 3 trial set $2, p=0.003$; trial set $3, p=0.0027$; trial set $4, p=0.012$; trial set $5, p=$ 0.0499 ; trial set $6, p=0.0223$; nicotine group, $n=8$; vehicle group, $n=7$ ). On day 4 , both nicotine- and vehicle-treated rats were given a challenge $\mathrm{EtOH}$ dose (1 $\mathrm{g} / \mathrm{kg}$, i.p.) after the baseline trial sets. Rotarod testing continued as usual at 15 min intervals. Animals that had received nicotine treatments on days 1-3 displayed significantly less $\mathrm{EtOH}$-induced motor impairment than did animals that had received vehicle treatments (Fig. 2; twoway RM ANOVA, $p=0.0004$ between treatments; HolmSidak test for multiple comparisons, $p=0.0268$ ). These

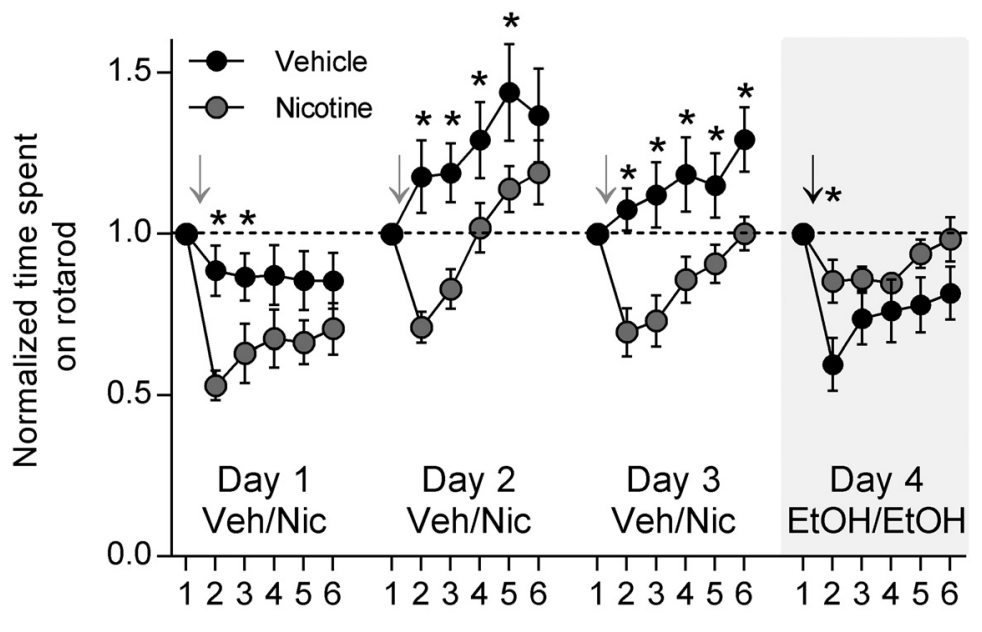

Trial Set

Fig. 2. Acute nicotine administration causes motor impairment, but repeated administration results in tolerance to EtOH-induced motor impairment. Rats that were previously trained on the rotarod were tested for motor performance over $4 \mathrm{~d}$. For the first $3 \mathrm{~d}$, rats were administered either nicotine $(0.1 \mathrm{mg} / \mathrm{kg}$, s.c.) or vehicle. Gray arrows indicate the time point at which nicotine was administered. On the fourth day, both nicotine- and vehicle-treated groups were challenged with $\mathrm{EtOH}$ and tested for motor performance on the rotarod. The black arrow indicates the time at which EtOH was given. Acute nicotine administration resulted in significant motor impairment over all $3 \mathrm{~d}$ compared with vehicle administration (ANOVA, $p<0.0001$ days 1, 2, 3; Holm-Sidak post hoc test, $* p<0.05$; nicotine: $n=8$, vehicle: $n=7$ ). Repeated nicotine administration, however, resulted in tolerance to EtOH-induced motor impairment compared with vehicle administration (ANOVA, $p<0.001$; Holm-Sidak post hoc test, $* p<0.05$ ). 
A

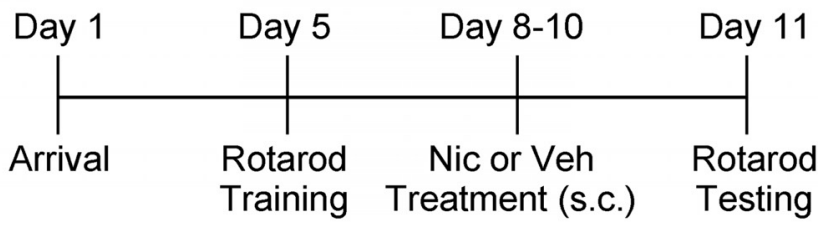

B

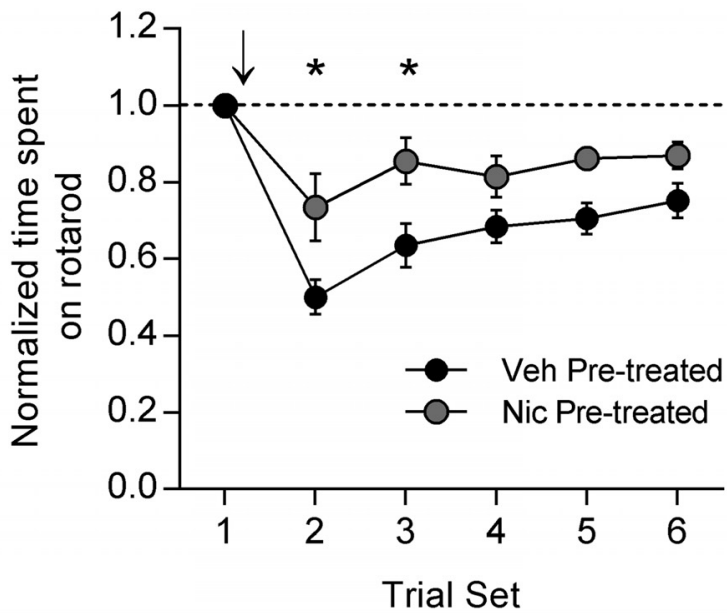

C

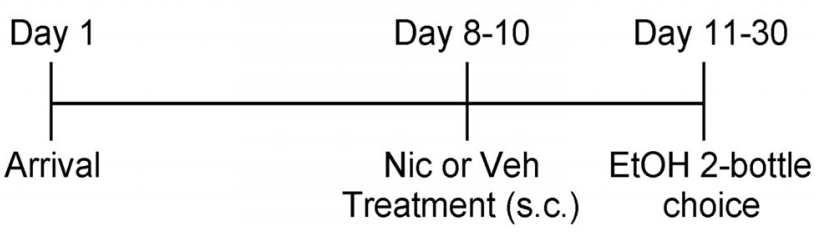

D

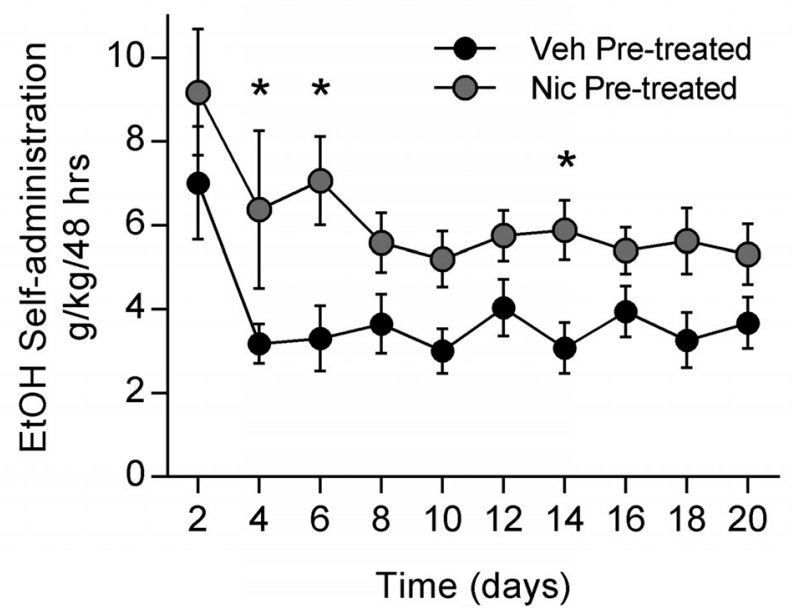

Fig. 3. Nicotine pretreatment results in tolerance to $\mathrm{EtOH}-$ induced motor impairment and increased EtOH self-administration. $\boldsymbol{A}$, Timeline for the rotarod experiment in which rats were pretreated with either nicotine or vehicle. $\boldsymbol{B}$, Animals previously trained on the accelerating rotarod and pretreated for $3 \mathrm{~d}$ with either nicotine $(0.1 \mathrm{mg} / \mathrm{kg}$, s.c., once per day) or vehicle were tested for the effects of EtOH $(1 \mathrm{~g} / \mathrm{kg}$, i.p.) on rotarod performance. Arrow indicates time at which acute EtOH was administered. Nicotine pretreated animals displayed less impairment on the rotarod after acute $\mathrm{EtOH}$ administration than did the
Fig. 3. continued

vehicle-treated animals (ANOVA, $p<0.05$; Holm-Sidak post hoc test, $* p<0.01 ; n=14$ for each group). $\boldsymbol{C}$, Timeline for the $\mathrm{EtOH}$ two-bottle choice self-administration experiment in which rats were pretreated with either nicotine or vehicle. $\boldsymbol{D}$, Animals pretreated with nicotine $(0.1 \mathrm{mg} / \mathrm{kg}$, s.c., once per day) or vehicle were given $24 \mathrm{~h}$ access to both a bottle of water and a bottle of $20 \% \mathrm{EtOH}$ for 20 d. Nicotine-pretreated animals selfadministered more EtOH than vehicle-pretreated animals (ANOVA, $p<0.01$; Holm-Sidak post hoc test, $* p<0.05 ; n=8$ for both groups).

data show that nicotine is not simply enhancing performance on the rotarod and thus offsetting the motorimpairing effects of EtOH. They also show that nicotine treatment does not seem to impact the rate of improvement of rotarod performance. Together, our findings suggest that nicotine pretreatment, in the absence of concomitant drug exposure, results in cross-tolerance with $\mathrm{EtOH}$ and that cross-tolerance between $\mathrm{EtOH}$ and nicotine attenuates $\mathrm{EtOH}$-induced motor impairment.

To further investigate this cross-tolerance without the confound of repeated rotarod testing, we trained animals on the rotarod and then pretreated with either nicotine $(0.1$ $\mathrm{mg} / \mathrm{kg}$, s.c., as base) or vehicle once per day for $3 \mathrm{~d}$. The day after the last injection, rotarod testing began, and both groups were given a challenge dose of $\mathrm{EtOH}(1 \mathrm{~g} / \mathrm{kg}$, i.p.) after baseline testing (Fig. 3A). Nicotine-pretreated animals were significantly less impaired on the rotarod in response to $\mathrm{EtOH}$ than were vehicle-pretreated animals (Fig. 3B; two-way RM ANOVA, $p=0.0358$ time $\times$ treatment interaction; Holm-Sidak test for multiple comparisons: trial set 2, $p=0.0038$; trial set $3, p=0.0063 ; n=$ 14 in each group). Nicotine pretreatment results in tolerance to $\mathrm{EtOH}$-induced motor impairment.

Next, we investigated whether this regimen of nicotine pretreatment would also enhance $\mathrm{EtOH}$ self-administration. After singly housing the rats, nicotine or vehicle pretreatment took place once per day for $3 \mathrm{~d}$. The rats were then given $24 \mathrm{~h}$ access to a water bottle and a bottle of $20 \% \mathrm{EtOH}$, as in the previous two-bottle choice paradigm, for $20 \mathrm{~d}$ (Fig. 3C). Nicotine pretreatment resulted in enhanced $\mathrm{EtOH}$ self-administration compared with vehicle pretreatment (Fig. 3D; two-way RM ANOVA, $p=0.005$ between treatments; Holm-Sidak test for multiple comparisons: day $4, p=0.011$; day $6, p=0.003$; day $14, p=$ 0.025 ; nicotine group, $n=16$; vehicle group, $n=15$ ). Note that the vehicle-pretreated groups in the ethanol experiments displayed higher EtOH self-administration during the first $10 \mathrm{~d}$ relative to the control animals in the nicotine experiment. This is most likely due to differences in stress, as the $\mathrm{EtOH}$ experiment required twice-daily injections, while the nicotine experiment involved injections only once per day. Previous studies have reported stress-induced enhancement of EtOH self-administration (Meyer et al., 2013), but the important observation here is that both $\mathrm{EtOH}$ and nicotine pretreatment elevated $\mathrm{EtOH}$ self-administration relative to control treatments. 
A

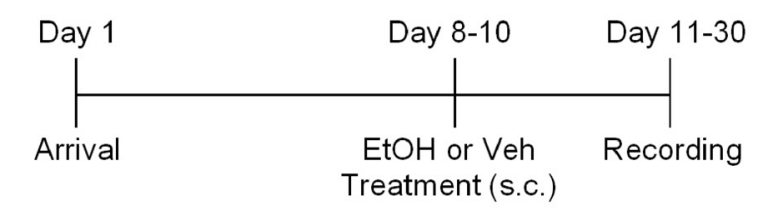

D
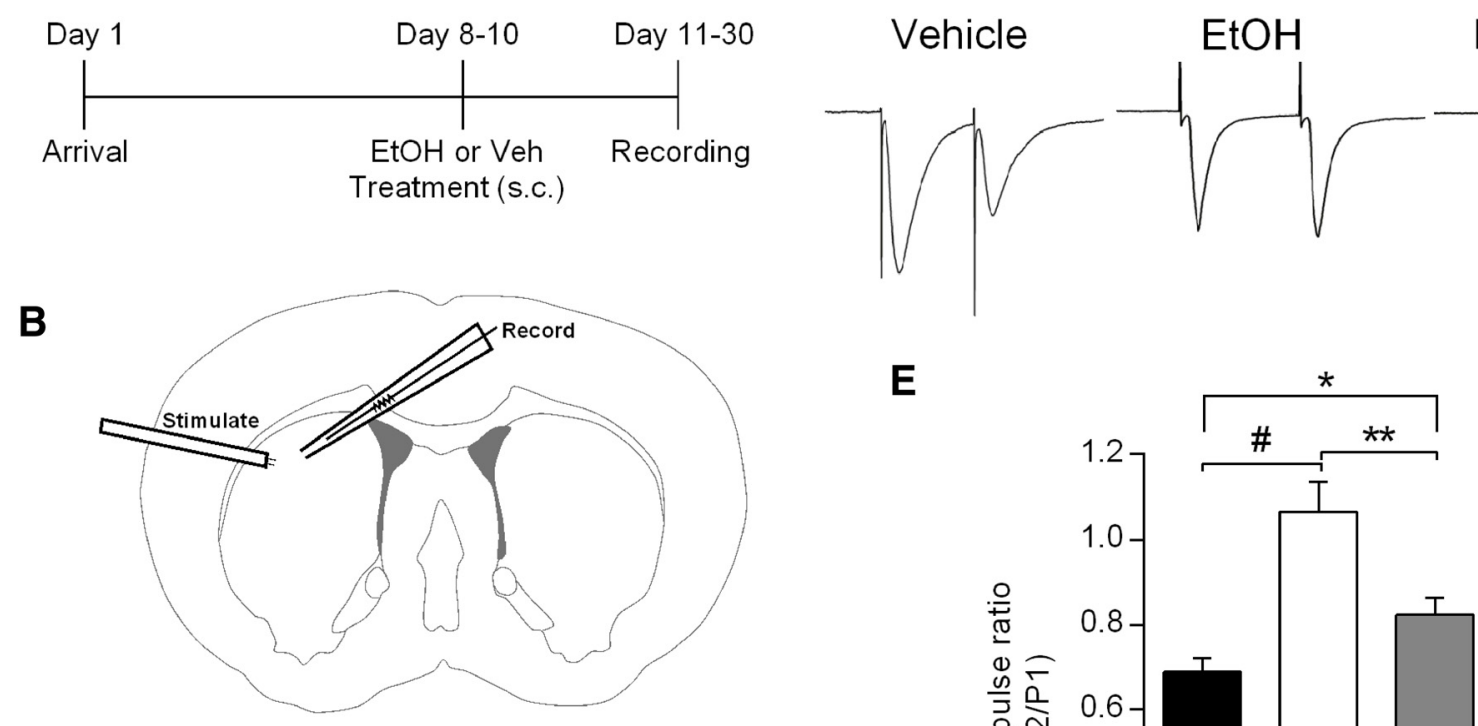

Nicotine
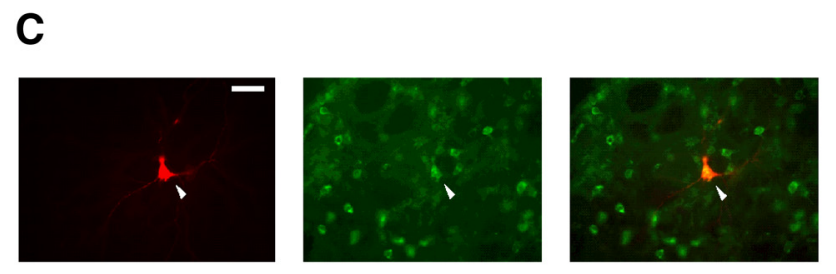

E

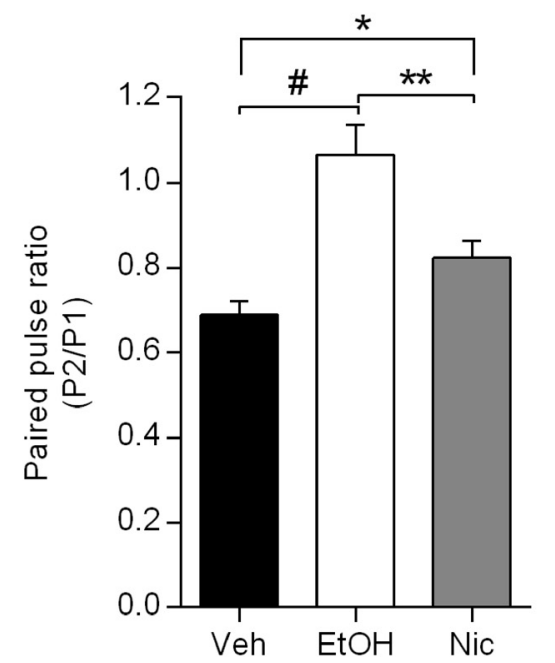

Fig. 4. EtOH and nicotine pretreatment increase the paired-pulse ratio in enkephalin-positive (putative $\mathrm{D}_{2}$ receptor-containing) MSNs in the DLS. A, Timeline for electrophysiology experiments in which rats were pretreated with EtOH (1 g/ $/ \mathrm{kg}$, s.c., twice per day), nicotine $(0.1 \mathrm{mg} / \mathrm{kg}$, s.c., once per day), or vehicle. B, Schematic showing the positioning of recording and stimulating electrodes in the DLS. C, Images of MSNs in the DLS. Arrowheads show the neuron that was recorded from. From left to right: representative biocytin-filled MSN (red); immunohistochemical labeling of enkephalin-positive MSNs (green); merged image (scale bar, $50 \mu \mathrm{m}$ ). All neurons included were putative $\mathrm{D}_{2}$ MSNs. $\boldsymbol{D}$, Representative traces showing the effects of vehicle, EtOH, or nicotine pretreatments on the paired-pulse ratio of EPSCs. $\boldsymbol{E}$, Summary of the effects of vehicle, EtOH, or nicotine pretreatment on paired-pulse ratios in putative $\mathrm{D}_{2}$-containing MSNs. EtOH and nicotine pretreatment both increased the paired-pulse ratio compared with vehicle pretreatment (ANOVA, $p<0.0001$; Holm-Sidak post hoc test, \#p<0.0001, $* p<0.05$ ), and EtOH pretreatment increased the paired-pulse ratio significantly more than nicotine pretreatment (**p < 0.01; vehicle: $n=19$; EtOH: $n=16$; nicotine: $n=23$; one cell/slice/rat).

\section{EtOH and nicotine pretreatment similarly modulate DLS cannabinoid signaling}

Because $\mathrm{EtOH}$ and nicotine have both been reported to impact cannabinoid signaling in the DLS, we wanted to investigate and compare the effects of our $\mathrm{EtOH}$ and nicotine pretreatment regimens on DLS synapses. We used slice electrophysiology to examine release probability at glutamatergic synapses onto enkephalin-positive (putative $\mathrm{D}_{2}$-containing) MSNs. Rats were exposed to the same pretreatment regimen of $\mathrm{EtOH}$, nicotine, or vehicle that resulted in tolerance to $\mathrm{EtOH}$-induced motor impairment and increased EtOH self-administration. The day after the last drug administration, coronal slices were taken for electrophysiological recordings (Fig. 4A). Recordings were restricted to the DLS, and stimulating electrodes were placed between the recording electrode and the corpus collosum (Fig. $4 B$ ) in order to preferentially stimulate cortical inputs. Recording pipettes were also filled with biocytin, so that we could later visualize the MSNs from which we made recordings. Immunohistochemistry for enkephalin was performed on these neurons, and all neurons included in our analyses were enkephalinpositive MSNs (Fig. 4C). Both EtOH and nicotine pretreatment resulted in increased paired-pulse ratios at these DLS synapses compared to vehicle pretreatment (Fig. $4 D, E$; one-way ANOVA, $p<0.0001$; Holm-Sidak test for multiple comparisons: $p<0.0001$, EtOH vs vehicle; $p=$ 0.0454 , nicotine vs vehicle). EtOH pretreatment also increased the PPR compared with nicotine pretreatment $(p=0.0017)$. This increase in paired-pulse ratio suggests that $\mathrm{EtOH}$ and nicotine pretreatment both decrease the probability of glutamate release at $D_{2}$-containing MSNs in the DLS.

This change in release probability is consistent with a role for endocannabinoid signaling in the DLS. If the effects of EtOH and nicotine pretreatments on PPR were due to changes in endocannabinoid signaling, then the effects of bath application of a CB1 receptor agonist might be occluded in these pretreated rats. To further investigate the potential role of DLS cannabinoid signaling in cross-tolerance between EtOH and nicotine, we again used slice electrophysiology and tested the effects of a 
bath-applied CB1 receptor agonist (Win 55,2-212, $5 \mu \mathrm{M}$ ). Rats were given the same pretreatments as in all prior experiments of vehicle, EtOH, or nicotine. In vehiclepretreated rats, bath application of Win 55,2-212 significantly decreased the amplitude of evoked EPSCs, but in $\mathrm{EtOH}-$ and nicotine-pretreated rats, Win 55,2-212 application failed to alter EPSC amplitude [Fig. 5A-C; paired $t$ test comparing $5 \mathrm{~min}$ of baseline with the last $10 \mathrm{~min}$ of Win 55,2-212 application within each treatment group: vehicle $(n=6), p<0.001$; EtOH $(n=7), p=0.384$; nicotine $(n=5), p=0.052$ ].

We also examined the effects of Win 55,2-212 application on PPRs in the three treatment groups. While Win 55,2-212 application increased the PPR as expected in vehicle-pretreated rats, the effects of Win 55,2-212 were indeed occluded in both $\mathrm{EtOH}$ - and nicotine-pretreated rats [Fig. $5 A, D, E$; paired $t$ test comparing $5 \mathrm{~min}$ of baseline with the last 10 min of Win 55,2-212 application within each treatment group: vehicle $(n=6), p=0.012$; $\mathrm{EtOH}$ $(n=7), p=0.992$; nicotine $(n=5), p=0.611]$. These data suggest that $\mathrm{EtOH}$ and nicotine pretreatment may have enhanced cannabinoid release and thus decreased CB1 receptor expression. These results indicate that pretreatment with either $\mathrm{EtOH}$ or nicotine results in similar modulation of endocannabinoid signaling in the DLS, and that this modulation may contribute to cross-tolerance between these two commonly abused drugs.

\section{Nicotine pretreatment occludes HFS-induced LTD}

To further examine the extent to which DLS synaptic plasticity underlies the observed behavioral effects of nicotine pretreatment, we tested LTD induction at corticostriatal synapses. Using the same stimulating electrode placement as that shown in Figure $4 B$, baseline EPSCs were recorded for $10 \mathrm{~min}$, followed by a $1 \mathrm{~s} \mathrm{HFS}$ train $(100 \mathrm{~Hz})$. EPSC amplitudes were then monitored for $30 \mathrm{~min}$. As shown in the raw traces in Figure $6 A$ and the time course data in Figure $6 B$, nicotine-pretreated animals showed less LTD following HFS than that observed in vehicle-pretreated rats. Comparing the averaged normalized EPSC amplitudes between the groups revealed significant occlusion of LTD induction in the nicotine-pretreated animals (Fig. 6C; $p<0.05$ with unpaired $t$ test).

\section{Discussion}

In this study, we have found that identical pretreatments with either nicotine or EtOH result in both tolerance to the motor-impairing effects of EtOH and increased EtOH selfadministration. These pretreatments also result in an increase in the paired-pulse ratio of evoked EPSCs and the occlusion of the effects of a CB1 agonist in putative $\mathrm{D}_{2}$-containing MSNs in the DLS. In addition, nicotine pretreatment also occluded HFS-induced LTD at these synapses.

The effects of nicotine on $\mathrm{EtOH}$-related behaviors are rarely examined without the concurrent administration of both drugs. Here we show that nicotine pretreatment alone results in increased EtOH self-administration, despite termination of nicotine administration $24 \mathrm{~h}$ prior to $\mathrm{EtOH}$ access. We also show that identical nicotine pre- treatment results in tolerance to the motor-impairing effects of $\mathrm{EtOH}$, suggesting that increased tolerance to $\mathrm{EtOH}$ leads to more EtOH consumption. That tolerance to $\mathrm{EtOH}$ and dependence go hand in hand is not a new idea (Pava and Woodward, 2012); however, we used identical pre-exposure paradigms to more conclusively examine how self-administration and tolerance relate to each other.

Nicotine was used to induce tolerance to $\mathrm{EtOH}$, which eliminates a confounding variable that is often built into experiments that attempt to explore this relationship by testing both drugs together. Our finding that nicotine pre-exposure produces tolerance to $\mathrm{EtOH}$ and is sufficient to enhance EtOH self-administration suggests that tolerance to EtOH is not simply a byproduct of increased $\mathrm{EtOH}$ consumption, but rather that tolerance to $\mathrm{EtOH}$ can precede and result in increased EtOH consumption. These findings suggest that a limited history with nicotine can impact EtOH-related behaviors even after nicotine exposure has ended. In human subjects, smoking history correlates with future $\mathrm{EtOH}$ dependence (John et al., 2003; Buu et al., 2014). Our findings suggest that prior nicotine exposure in humans may facilitate the development of $\mathrm{EtOH}$ tolerance and habitual $\mathrm{EtOH}$ consumption.

This idea is supported by past studies in humans, which found correlations between decreased sensitivity to the effects of $\mathrm{EtOH}$ and increased risk for alcohol use disorders (Trim et al., 2009; Corbin et al., 2013). Repeated exposures to $\mathrm{EtOH}$ may also selectively reduce the experience of the more aversive effects of EtOH (cognitive/ motor impairments), while leaving the rewarding effects less affected or even sensitized (Ding et al., 2012; Fritz et al., 2014). Despite the complexities underlying tolerance and sensitization (Blomqvist et al., 1996; Söderpalm et al., 2000; Cohen et al., 2002; López-Moreno et al., 2008), our findings support the hypothesis that crosstolerance between nicotine and $\mathrm{EtOH}$ contributes to the frequent coabuse of these drugs.

In addition to exploring the behavioral outcomes of $\mathrm{EtOH}$ and nicotine pretreatments, we also tested neuroplasticity changes in the DLS, as neuroplasticity is known to be important for habit formation, motor performance, and motor learning. Therefore, we tested the impact of $\mathrm{EtOH}$ or nicotine pretreatment on plasticity that influence locomotion and drug pursuit. We show that pretreatment with either nicotine or EtOH induces changes in pairedpulse ratio in recordings from putative $D_{2}$-expressing MSNs in the DLS that are consistent with the induction of LTD. This interpretation is supported by the lack of effect of cannabinoid receptor agonist on EPSC amplitude and $\mathrm{P} 2 / \mathrm{P} 1$ ratio in striatal brain slices from nicotine- or $\mathrm{EtOH}-$ pretreated rats. We further show that high-frequency stimulation of corticostriatal inputs to the DLS, which induced LTD in slices from vehicle-treated animals, did not induce LTD in slices from nicotine pretreated rats. Our working model is that nicotine induces LTD at the excitatory inputs to $\mathrm{D}_{2}$-expressing MSN in the DLS and occludes subsequent LTD induction, either by CB1 agonist or HFS. These data suggest that nicotine may induce tolerance to the motor-impairing effects of $\mathrm{EtOH}$ and 
A

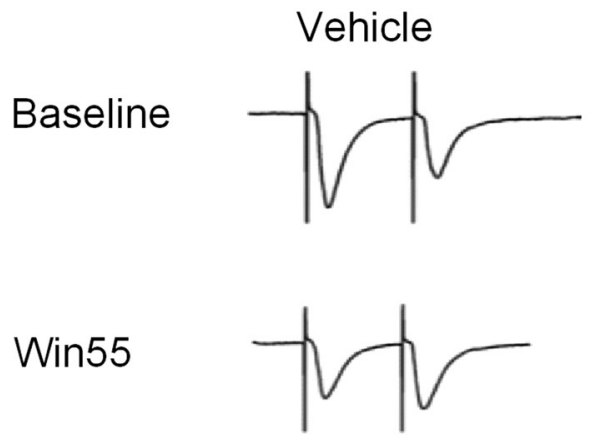

B

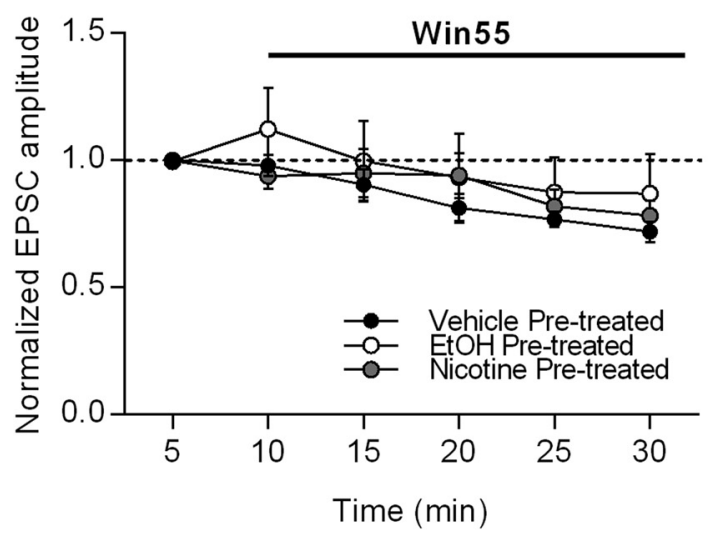

C

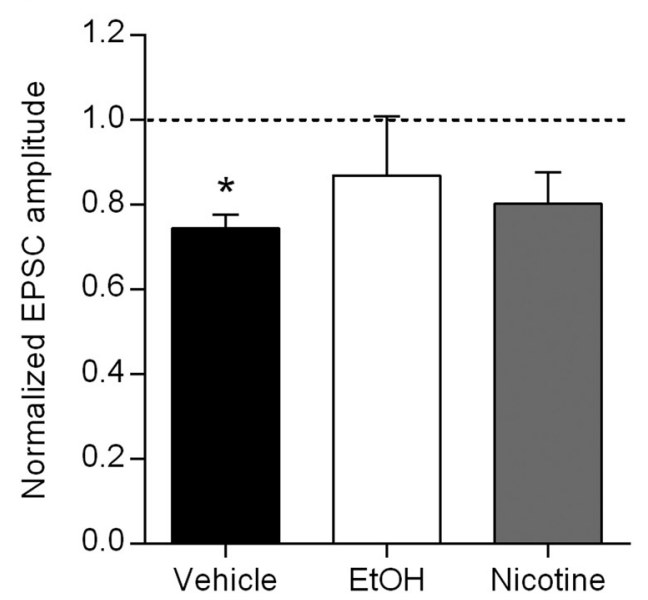

$\mathrm{EtOH}$
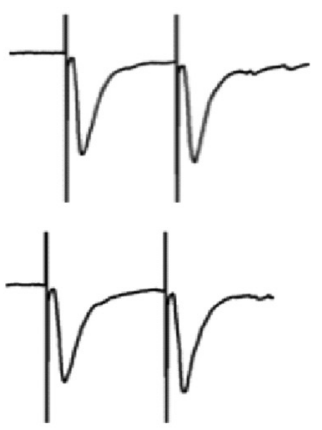

D
Nicotine
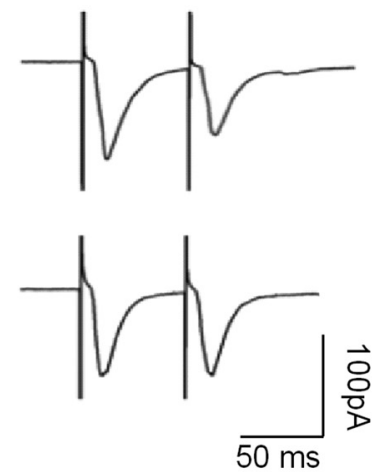

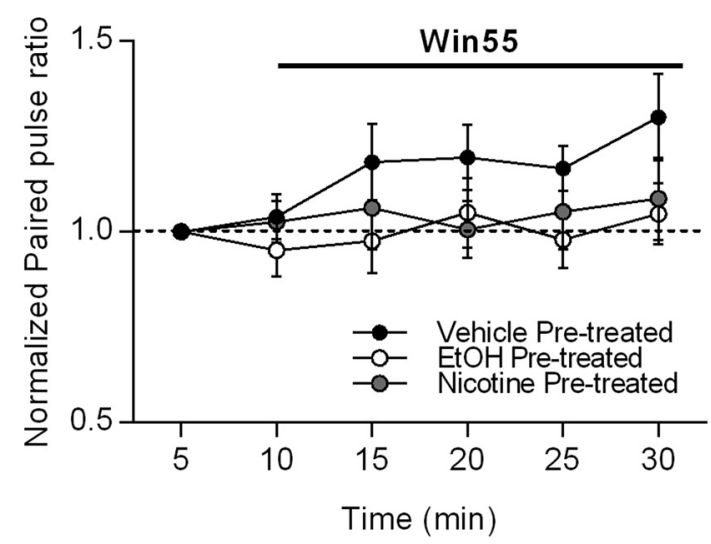

E

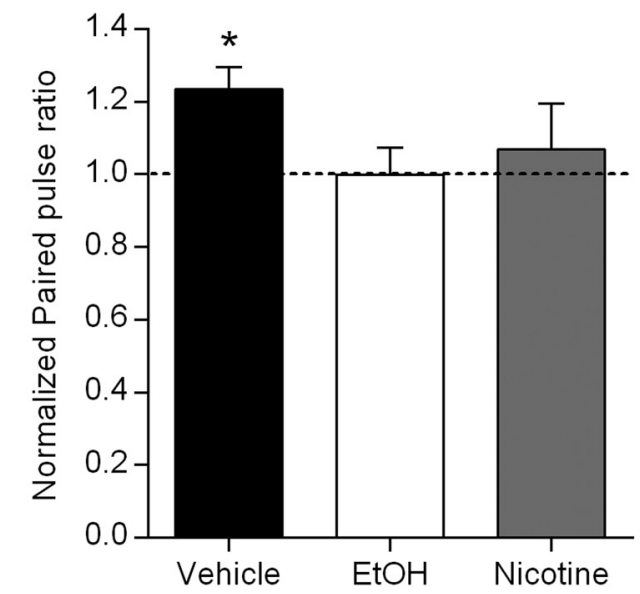

Fig. 5. Nicotine or EtOH pretreatment occludes the effects of the CB1 receptor agonist on synaptic transmission in enkephalinpositive MSNs in the DLS. $\boldsymbol{A}$, Representative traces of evoked EPSCs in putative $\mathrm{D}_{2}$-containing MSNs from rats that had been pretreated with vehicle, EtOH, or nicotine during baseline and during application of the CB1 receptor agonist Win 55,2-212 (5 $\mu \mathrm{M})$. $\boldsymbol{B}$, Time course for the effects of Win 55, 2-212 on evoked EPSC amplitudes in each of the pretreatment groups. $\boldsymbol{C}$, Summary data showing that the inhibitory effect of Win 55, 2-212 was only present in vehicle pretreated animals (paired $t$ test baseline vs Win 55 , 2-212, $* p<0.05$; vehicle, $n=6$; EtOH, $n=7$; nicotine, $n=5$ ). $\boldsymbol{D}$, Time course for the effects of Win 55, 2-212 on PPR in each of the pretreatment groups. $\boldsymbol{E}$, Summary data showing that Win 55, 2-212 only increases the PPR in vehicle-pretreated rats (paired $t$ test baseline vs Win 55, 2-212, $* p<0.05$; vehicle, $n=6$; EtOH, $n=7$; nicotine, $n=5$ ).

increase $\mathrm{EtOH}$ self-administration through changes in corticostriatal synaptic plasticity. These correlative findings support the model that the DLS contributes to drug reward and habit formation (Gerdeman et al., 2003), and future studies will be required to establish causal connections. 
A
Vehicle
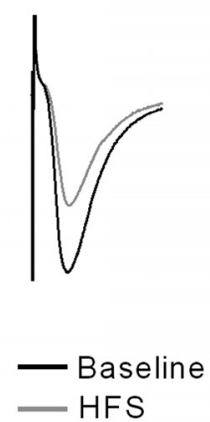

Nicotine
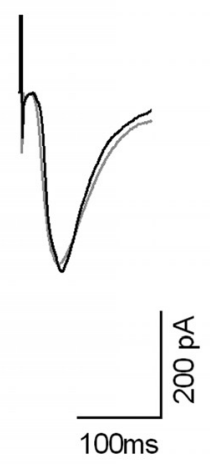

B

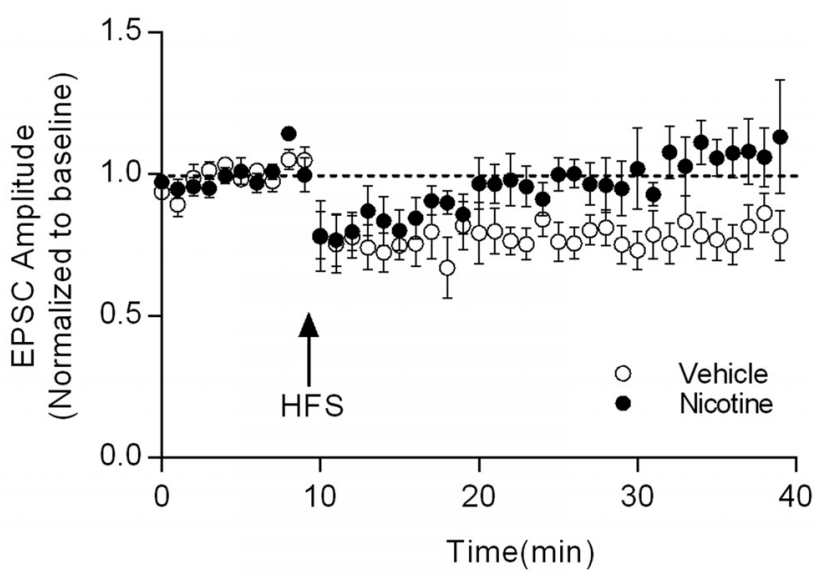

C

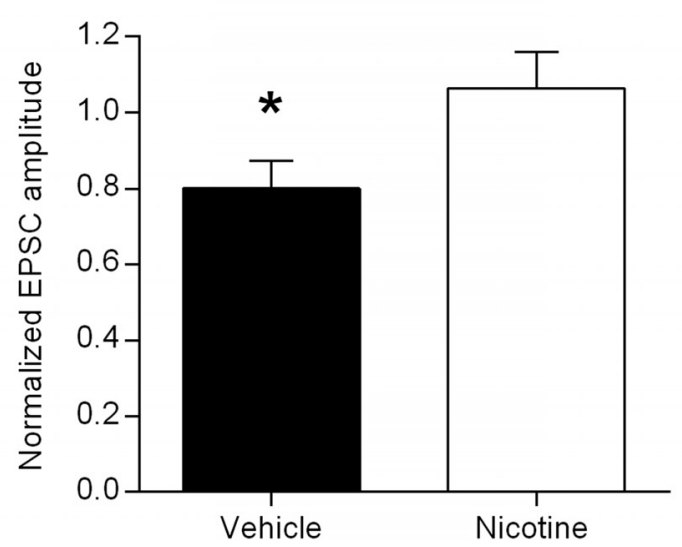

Fig. 6. Nicotine pretreatment occludes HFS-induced LTD in enkephalin-positive MSNs in the DLS. $\boldsymbol{A}$, Representative EPSCs from putative $\mathrm{D}_{2}$-containing MSNs from vehicle- and nicotine-pretreated rats during baseline and after HFS. $\boldsymbol{B}$, Time course of the effects HFS on evoked EPSC amplitudes in vehicle- (open symbols) and nicotine(filled symbols) pretreated groups. $\boldsymbol{C}$, Summary data showing that HFS induces LTD of the excitatory inputs to DLS MSNs in vehiclepretreated rats, but not in nicotine-pretreated rats (unpaired $t$ test baseline vs HFS, $* p<0.05$; vehicle, $n=9$; nicotine, $n=7$ ).
Although we placed our stimulating electrode close to the border between cortex and the DLS to preferentially stimulate corticostriatal inputs, it is possible that thalamostriatal projections are also active under these conditions. As reported by Wu et al. (2015), frequency-dependent synaptic plasticity and endocannabinoid expression are stronger and more prevalent in corticostriatal relative to thalamostriatal inputs to the DLS. Corticostriatal synaptic plasticity is thought to underlie motor learning and behavioral plasticity, while thalamostriatal inputs carry sensory information to encode salience and facilitate attentional focus. While our stimulation paradigm does not rule out the sampling of thalamic inputs, both the paired-pulse ratio and HFS-induced LTD measurements preferentially assess the effects of nicotine and $\mathrm{EtOH}$ on corticostriatal inputs, and we contend that these modifications are relevant to the behavioral end points examined here.

Previous work has implicated endocannabinoid signaling in tolerance to both $\mathrm{EtOH}$ and nicotine and in the rewarding effects of both drugs (Basavarajappa, 2007; Hungund and Yaragudri, 2009; Gamaleddin, 2015). EtOH and nicotine both cause hyperactive endocannabinoid signaling, which results in a downregulation of CB1 receptors in the striatum (Basavarajappa et al., 1998; Cohen et al., 2005). These changes in endocannabinoid signaling have also been linked to LTD at corticostriatal synapses (Gerdeman et al., 2002; DePoy et al., 2013, 2015), which is consistent with our findings. CB1 antagonism or genetic deletion reduces or eliminates the effects $\mathrm{EtOH}$ or nicotine pretreatment on EtOH self-administration (Poncelet et al 2003; Thanos et al 2005). Together, these findings support the idea that the CB1 receptor system may provide target for interfering with high $\mathrm{EtOH}$ consumption and its impact on the progression to addiction.

Many drug exposure paradigms used in those related studies were of longer duration than the pretreatment used here; therefore, our findings highlight the limited number of drug exposures required to cause dysregulation of endocannabinoid signaling in the DLS and profound behavioral changes. Additionally, the effects of nicotine exposure on endocannabinoid signaling have never been directly compared with those of EtOH. That the same pretreatment with either drug results in similar behavioral outcomes and similar neuroplasticity changes suggests that endocannabinoid signaling in the DLS is critical in mediating cross-tolerance between and frequent coabuse of $\mathrm{EtOH}$ and nicotine.

\section{References}

Acheson A, Mahler SV, Chi H, De Wit H (2006) Differential effects of nicotine on alcohol consumption in men and women. Psychopharmacology (Berl) 186:54-63. CrossRef Medline

Adermark L, Clarke RBC, Söderpalm B, Ericson M (2011) Ethanolinduced modulation of synaptic output from the dorsolateral striatum in rat is regulated by cholinergic interneurons. Neurochem Int 58:693-699. CrossRef Medline

Barrett SP, Tichauer M, Leyton M, Pihl RO (2006) Nicotine increases alcohol self-administration in non-dependent male smokers. Drug Alcohol Depend 81:197-204. CrossRef Medline

Basavarajappa BS (2007) The endocannabinoid signaling system: a potential target for next-generation therapeutics for alcoholism. Mini Rev Med Chem 7:769-779. Medline 
Basavarajappa BS, Cooper TB, Hungund BL (1998) Chronic ethanol administration down-regulates cannabinoid receptors in mouse brain synaptic plasma membrane. Brain Res 793:212-218. Medline

Batel P, Pessione F, Maitre C, Rueff B (1995) Relationship between alcohol and tobacco dependencies among alcoholics who smoke. Addiction 90:977-980. Medline

Batista LC, Prediger RDS, Morato GS, Takahashi RN (2005) Blockade of adenosine and dopamine receptors inhibits the development of rapid tolerance to ethanol in mice. Psychopharmacology (Berl) 181:714-721. CrossRef Medline

Biała G, Budzyńska B (2010) Rimonabant attenuates sensitization, cross-sensitization and cross-reinstatement of place preference induced by nicotine and ethanol. Pharmacol Rep 62:797-807. CrossRef

Blomqvist O, Ericson M, Johnson D, Engel J, Söderpalm B (1996) Voluntary ethanol intake in the rat: effects of nicotinic acetylcholine receptor blockade or subchronic nicotine treatment. Eur J Pharmacol 314:257-267. Medline

Burch JB, de Fiebre CM, Marks MJ, Collins AC (1988) Chronic ethanol or nicotine treatment results in partial cross-tolerance between these agents. Psychopharmacology (Berl) 95:452-458. Medline

Buu A, Dabrowska A, Mygrants M, Puttler LI (2014) Gender differences in the developmental risk of onset of alcohol, nicotine, and marijuana use and the effects of nicotine and marijuana use on alcohol outcomes. J Stud Alcohol Drugs 75:850-858. CrossRef

Ceballos NA (2006) Tobacco use, alcohol dependence, and cognitive performance. J Gen Psychol 133:375-388. CrossRef Medline

Chen C, Omiya Y, Yang S (2014) Dissociating contributions of ventral and dorsal striatum to reward learning. J Neurophysiol 114:13641366.

Cohen C, Perrault G, Voltz C, Steinberg R, Soubrié P (2002) SR141716, a central cannabinoid $(\mathrm{CB}(1))$ receptor antagonist, blocks the motivational and dopamine-releasing effects of nicotine in rats. Behav Pharmacol 13:451-463. Medline

Cohen C, Kodas E, Griebel G (2005) CB1 receptor antagonists for the treatment of nicotine addiction. Pharmacol Biochem Behav 81: 387-395. CrossRef Medline

Collins AC, Burch JB, De Fiebre CM, Marks MJ (1988) Tolerance to and cross tolerance between ethanol and nicotine. Pharmacol Biochem Behav 29:365-373. Medline

Collins AC, Wilkins LH, Slobe BS, Cao JZ, Bullock AE (1996) Longterm ethanol and nicotine treatment elicit tolerance to ethanol. Alcohol Clin Exp Res 20:990-999. Medline

Corbin WR, Scott C, Leeman RF, Fucito LM, Toll BA, O'Malley SS (2013) Early subjective response and acquired tolerance as predictors of alcohol use and related problems in a clinical sample. Alcohol Clin Exp Res 37:490-497. CrossRef Medline

Da Silva GE, Morato GS, Takahashi RN (2001) Rapid tolerance to Delta(9)-tetrahydrocannabinol and cross-tolerance between ethanol and Delta(9)-tetrahydrocannabinol in mice. Eur J Pharmacol 431:201-207. Medline

Daeppen JB, Smith TL, Danko GP, Gordon L, Landi NA, Nurnberger JI, Bucholz KK, Raimo E, Schuckit MA (2002) Clinical correlates of cigarette smoking and nicotine dependence in alcohol-dependent men and women. The Collaborative Study Group on the Genetics of Alcoholism. Alcohol Alcohol 35:171-175. CrossRef

DePoy L, Daut R, Brigman JL, MacPherson K, Crowley N, GunduzCinar O, Pickens CL, Cinar R, Saksida LM, Kunos G, Lovinger DM, Bussey TJ, Camp MC, Holmes A (2013) Chronic alcohol produces neuroadaptations to prime dorsal striatal learning. Proc Natl Acad Sci U S A 110:14783-14788. CrossRef Medline

DePoy L, Daut R, Wright T, Camp M, Crowley N, Noronha B, Lovinger D, Holmes A (2015) Chronic alcohol alters rewarded behaviors and striatal plasticity. Addict Biol 20:345-348. CrossRef

Deutsch J, Koopmans H (1973) Preference enhancement for alcohol by passive exposure. Science 179:1242-1243. Medline

Ding ZM, Katner SN, Rodd ZA, Truitt W, Hauser SR, Deehan GA, Engleman EA, McBride WJ (2012) Repeated exposure of the pos- terior ventral tegmental area to nicotine increases the sensitivity of local dopamine neurons to the stimulating effects of ethanol. Alcohol 46:217-223. CrossRef

Fidler TL, Dion AM, Powers MS, Ramirez JJ, Mulgrew JA, Smitasin PJ, Crane AT, Cunningham CL (2011) Intragastric self-infusion of ethanol in high- and low-drinking mouse genotypes after passive ethanol exposure. Genes Brain Behav 10:264-275. CrossRef Medline

Fritz BM, Cordero KA, Barkley-Levenson AM, Metten P, Crabbe JC Boehm SL (2014) Genetic relationship between predisposition for binge alcohol consumption and blunted sensitivity to adverse effects of alcohol in mice. Alcohol Clin Exp Res 38:1284-1292. CrossRef Medline

Funk D, Marinelli PW, Lê AD (2006) Biological processes underlying co-use of alcohol and nicotine: neuronal mechanisms, crosstolerance, and genetic factors. Alcohol Res Heal 29:186-192. Medline

Gamaleddin IH (2015) Role of the endogenous cannabinoid system in nicotine addiction: novel insights. Front Psychiatry 6:41. CrossRef

Garção P, Szabó EC, Wopereis S, Castro AA, Tomé AR, Prediger RD, Cunha RA, Agostinho P, Köfalvi A (2013) Functional interaction between pre-synaptic $\alpha 6 \beta 2$-containing nicotinic and adenosine $\mathrm{A} 2 \mathrm{~A}$ receptors in the control of dopamine release in the rat striatum. Br J Pharmacol 169:1600-1611. CrossRef Medline

Gerdeman GL, Ronesi J, Lovinger DM (2002) Postsynaptic endocannabinoid release is critical to long-term depression in the striatum. Nat Neurosci 5:446-451. CrossRef Medline

Gerdeman GL, Partridge JG, Lupica CR, Lovinger DM (2003) It could be habit forming: drugs of abuse and striatal synaptic plasticity. Trends Neurosci 26:184-192. CrossRef Medline

Glautier S, Clements K, White JAW, Taylor C, Stolerman IP (1996) Alcohol and the reward value of cigarette smoking. Behav Pharmacol 7:144-154. Medline

González S, Grazia Cascio M, Fernández-Ruiz J, Fezza F, Di Marzo V, Ramos JA (2002) Changes in endocannabinoid contents in the brain of rats chronically exposed to nicotine, ethanol or cocaine. Brain Res 954:73-81. CrossRef

Hertling I, Ramskogler K, Dvorak A, Klingler A, Saletu-Zyhlarz G, Schoberberger R, Walter H, Kunze M, Lesch OM (2005) Craving and other characteristics of the comorbidity of alcohol and nicotine dependence. Eur Psychiatry 20:442-450. CrossRef Medline

Hungund BL, Basavarajappa BS (2000) Distinct differences in the cannabinoid receptor binding in the brain of C57BL/6 and DBA/2 mice, selected for their differences in voluntary ethanol consumption. J Neurosci Res 60:122-128. Medline

Hungund BL, Yaragudri KV (2009) Role of the Endocannabinoid System in Alcohol-Related Behaviors. Open Neuropsychopharmacol J 2:31-39. CrossRef

John U, Meyer C, Rumpf HJ, Schumann A, Thyrian JR, Hapke U (2003) Strength of the relationship between tobacco smoking, nicotine dependence and the severity of alcohol dependence syndrome criteria in a population-based sample. Alcohol Alcohol 38:606-612. CrossRef

Johnson BA (2004) Topiramate-induced neuromodulation of corticomesolimbic dopamine function: a new vista for the treatment of comorbid alcohol and nicotine dependence? Addict Behav 29: 1465-1479. CrossRef Medline

King A, McNamara P, Angstadt M, Phan KL (2010) Neural substrates of alcohol-induced smoking urge in heavy drinking nondaily smokers. Neuropsychopharmacology 35:692-701. CrossRef Medline

Lê AD, Funk D, Lo S, Coen K (2014) Operant self-administration of alcohol and nicotine in a preclinical model of co-abuse. Psychopharmacology (Berl) 231:4019-4029. CrossRef

Lemos JI, Takahashi RN, Morato GS (2007) Effects of SR141716 and WIN 55,212-2 on tolerance to ethanol in rats using the acute and rapid procedures. Psychopharmacology (Berl) 194:139-149. CrossRef Medline

López-Moreno JA, Scherma M, Rodríguez de Fonseca F, GonzálezCuevas G, Fratta W, Navarro M (2008) Changed accumbal respon- 
siveness to alcohol in rats pre-treated with nicotine or the cannabinoid receptor agonist WIN 55,212-2. Neurosci Lett 433: 1-5. CrossRef Medline

Marco EM, Granstrem O, Moreno E, Llorente R, Adriani W, Laviola G, Viveros MP (2007) Subchronic nicotine exposure in adolescence induces long-term effects on hippocampal and striatal cannabinoid-CB1 and mu-opioid receptors in rats. Eur J Pharmacol 557:37-43. CrossRef Medline

McClure EA, Campbell ANC, Pavlicova M, Hu M, Winhusen T, Vandrey RG, Ruglass LM, Covey LS, Stitzer ML, Kyle TL, Nunes EV (2015) Cigarette smoking during substance use disorder treatment: secondary outcomes from a National Drug Abuse Treatment Clinical Trials Network study. J Subst Abuse Treat 53:39-46. CrossRef

McGinty JF (2007) Co-localization of GABA with other neuroactive substances in the basal ganglia. Prog Brain Res 160:273-284. CrossRef Medline

Meng ZH, Pennington SN, Dar MS (1998) Rat striatal adenosinergic modulation of ethanol-induced motor impairment: possible role of striatal cyclic AMP. Neuroscience 85:919-930. Medline

Meyer EM1, Long V, Fanselow MS, Spigelman I (2013) Stress increases voluntary alcohol intake, but does not alter established drinking habits in a rat model of posttraumatic stress disorder. Alcohol Clin Exp Res 37:566-574. CrossRef

Miller NS, Gold MS (1998) Comorbid cigarette and alcohol addiction: epidemiology and treatment. J Addict Dis 17:55-66. CrossRef Medline

Morrow AL, Porcu P, Boyd KN, Grant KA (2006) Hypothalamicpituitary-adrenal axis modulation of GABAergic neuroactive steroids influences ethanol sensitivity and drinking behavior. Dialogues Clin Neurosci 8:463-477. Medline

Pava MJ, Woodward JJ (2012) A review of the interactions between alcohol and the endocannabinoid system: implications for alcohol dependence and future directions for research. Alcohol 46:185204. CrossRef Medline

Paxinos G, Watson C (1998) The rat brain in stereotaxic coordinates, Ed 4. San Diego: Academic.

Perkins KA, Sexton JE, DiMarco A, Grobe JE, Scierka A, Stiller RL (1995) Subjective and cardiovascular responses to nicotine combined with alcohol in male and female smokers. Psychopharmacology (Berl) 119:205-212. Medline

Poncelet M, Maruani J, Calassi R, Soubrié P (2003) Overeating, alcohol and sucrose consumption decrease in $\mathrm{CB} 1$ receptor deleted mice. Neurosci Lett 343:216-218. Medline

Potthoff AD, Ellison G, Nelson L (1983) Ethanol intake increases during continuous administration of amphetamine and nicotine, but not several other drugs. Pharmacol Biochem Behav 18:489493. CrossRef
Rose JE, Brauer LH, Behm FM, Cramblett M, Calkins K, Lawhon D (2002) Potentiation of nicotine reward by alcohol. Alcohol Clin Exp Res 26:1930-1931. CrossRef Medline

Sayette M (2002) The effects of alcohol on cigarette craving. Alcohol Clin Exp Res 26:1925-1927. CrossRef Medline

Schuckit MA, Edenberg HJ, Kalmijn J, Flury L, Smith TL, Reich T, Bierut L, Goate A, Foroud T (2001) A genome-wide search for genes that relate to a low level of response to alcohol. Alcohol Clin Exp Res 25:323-329. Medline

Siemens AJ, Doyle OL (1979) Cross-tolerance between delta9tetrahydrocannabinol and ethanol: the role of drug disposition. Pharmacol Biochem Behav 10:49-55. Medline

Söderpalm B, Ericson M, Olausson P, Blomqvist O, Engel JA (2000) Nicotinic mechanisms involved in the dopamine activating and reinforcing properties of ethanol. Behav Brain Res 113:85-96. Medline

Sprague GL, Craigmill AL (1976) Ethanol and delta-9-tetrahydrocannabinol: mechanism for cross-tolerance in mice. Pharmacol Biochem Behav 5:409-415. Medline

Thanos PK, Dimitrakakis ES, Rice O, Gifford A, Volkow ND (2005) Ethanol self-administration and ethanol conditioned place preference are reduced in mice lacking cannabinoid CB1 receptors. Behav Brain Res 164:206-213. CrossRef Medline

Trim RS, Schuckit MA, Smith TL (2009) The relationships of the level of response to alcohol and additional characteristics to alcohol use disorders across adulthood: a discrete-time survival analysis. Alcohol Clin Exp Res 33:1562-1570. CrossRef Medline

Valjent E, Mitchell J (2002) Behavioural and biochemical evidence for interactions between $\Delta 9$-tetrahydrocannabinol and nicotine. $\mathrm{Br} \mathrm{J}$ Pharmacol 135:564-578. CrossRef

Vinod KY, MacCioni P, Garcia-Gutierrez MS, Femenia T, Xie S, Carai MAM, Manzanares J, Cooper TB, Hungund BL, Colombo G (2012) Innate difference in the endocannabinoid signaling and its modulation by alcohol consumption in alcohol-preferring $\mathrm{SP}$ rats. Addict Biol 17:62-75. CrossRef Medline

Werner DF, Swihart AR, Ferguson C, Lariviere WR, Harrison NL, Homanics GE (2009) Alcohol-induced tolerance and physical dependence in mice with ethanol insensitive a1 GABA A receptors. Alcohol Clin Exp Res 33:289-299. CrossRef Medline

Wu YW, Kim JI, Tawfik VL, Lalchandani RR, Scherrer G, Ding JB (2015) Input- and cell-type-specific endocannabinoid-dependent LTD in the striatum. Cell Rep 10:75-87. CrossRef Medline

York JL, Hirsch JA (1995) Drinking patterns and health status in smoking and nonsmoking alcoholics. Alcohol Clin Exp Res 19: 666-673. Medline

Zhao S, Ting JT, Atallah HE, Qiu L, Tan J, Gloss B, Augustine GJ, Deisseroth K, Luo M, Graybiel AM, Feng G (2011) Cell typespecific channelrhodopsin-2 transgenic mice for optogenetic dissection of neural circuitry function. Nat Methods 8:745-752. Medline 